\title{
Use of Synchronous e-Learning at University Degrees
}

\author{
ANA FITA, ${ }^{1}$ JOSE F. MONSERRAT, ${ }^{2}$ GERMÁN MOLTÓ, ${ }^{3}$ EVA M. MESTRE, ${ }^{4}$ \\ ADRIÁN RODRIGUEZ-BURRUEZO ${ }^{1}$ \\ ${ }^{1}$ Departamento Biotecnología, Universitat Politècnica de València, Camino de Vera 14, Valencia PC 46022, Spain \\ ${ }^{2}$ Departamento Comunicaciones, Universitat Politècnica de València, Camino de Vera 14, Valencia PC 46022, Spain \\ ${ }^{3}$ Departamento Sistemas Informáticos y Computación, Universitat Politècnica de València, Camino de Vera 14, Valencia \\ PC 46022, Spain
}

${ }^{4}$ Departamento Lingüística Aplicada, Universitat Politècnica de València, Camino de Vera 14, Valencia PC 46022, Spain

Received 20 May 2016; accepted 9 October 2016

\begin{abstract}
Different types of Course Management Systems (CMS) are fully integrated in conventional and online courses in many Universities degrees. Although they are suitable for lecturer-student information sharing, their asynchronous nature prevents an efficient interaction, which may hamper the learning process. As an alternative, synchronous virtual learning platforms can help fill the gaps in traditional CMS. However, there is very little feedback regarding its use in higher education. The Universitat Politècnica de València introduced in $2010 \mathrm{a}$ synchronous e-learning platform, named Poli[ReunióN], an Adobe Connect-based online service. Poli[ReunióN] provides virtual sessions where interaction between lecturers and students is enabled by means of audio/videoconferences and software application sharing. By following this path, Poli[ReunióN] provides an opportunity for planning new educational experiences where technology may help to achieve new learning objectives. However, the implementation of this tool still needs to be explored. In order to check its usefulness, we have performed a multidisciplinary learning experience involving a wide range of subjects over several degrees: Private Telecommunication Systems (degree in Telecommunications Engineering), Algorithms and Data Structure (degree in Computer Sciences), English for International Tourism (degree in Tourism Management), Genetics and Plant Breeding (degree in Agricultural Engineering), and a specific course for teachers' training. The advantages and disadvantages of the use of Poli[ReunióN] in tutoring and in different learning activities proposed in the aforementioned degrees are discussed from both perspectives-lecturers and students. These experiences may help lecturers and other education professionals to adopt similar e-learning tools. (c) 2016 Wiley Periodicals, Inc. Comput Appl Eng Educ 24:982-993, 2016; View this article online at wileyonlinelibrary.com/journal/ cae; DOI 10.1002/cae.21773
\end{abstract}

Keywords: synchronous virtual learning; higher education; tutorship; collaborative work

\section{INTRODUCTION}

Since the early 1990's, a number of courses have been provided by means of a variety of telecommunication methods (e.g., via e-mail, computer conferencing, satellite delivery, etc.). In recent years, the increase in the number of computers available per family, improved bandwidth and connection speeds and the greater degree of expansion of the Information and Communication Technologies

Correspondence to A. Fita (anfifer@upvnet.upv.es).

(C) 2016 Wiley Periodicals, Inc.
(ICT) have led to the proliferation of new technological tools available over the Internet to complement or substitute traditional teaching [1]. In fact, on-line lessons based on teaching modules are now common in most types of courses. Frequently, these on-line lessons use Course Management Systems (CMS), also known as a Learning Management System (LMS), or a Virtual Learning Environment (VLE) such as Sakai ${ }^{\mathrm{TM}}$, Moodle ${ }^{\mathrm{TM}}$, Itslearning ${ }^{\mathrm{TM}}$, etc. Usually, these platforms provide a series of sections intended to cover different parts of the teaching activity but, apart from the chatting options, they promote asynchronous teacher-student interaction. The asynchronous nature of these platforms presents both advantages and disadvantages. The main advantage is that students are free to carry out their work or follow the lesson 
whenever they can within the time established to complete the task. The main drawback is the lack of fluent and face-to-face interaction with the teacher. Due to the asynchronous nature of many of the CMS, it is difficult to use them for any teaching activity that involves teacher-student interaction or student-student interaction, where participants share time but not necessarily space. These interactions are of paramount importance in the learning process. Indeed, many studies are witness to the fact that distance learning cannot be completed without interpersonal interaction [2-4].

In this respect, Synchronous Virtual e-Learning tools (SVL), also known as webinar tools, can overcome this limitation as they provide, for instance, the opportunity to: (1) watch the teacher and talk to him/her, (2) share documents instantly, and (3) directly follow what the teacher types onto the computer (as in a e-blackboard). Therefore, synchronous tools are able to provide an experience similar to that of a regular class or a meeting, and are useful for tutorships, on-line courses, regular courses (for students who cannot physically attend the class), or seminars provided by colleagues in videoconferencing format. International companies worldwide are adopting SVL, not only for meetings but also for training and refresher courses aimed at their employees, being webinars more and more common. With these tools, companies save on travelling expenses and can access knowledge and technology in an efficient way.

In academia, the importance of SVL tools is growing fast and very few Universities lack virtual classrooms, especially for distance learning. In the market there are different software available. One of the most popular is Elluminate ${ }^{\mathrm{TM}}$ (now Blackboard), which provides advanced teleconferencing applications useful for teaching. Another one is Adobe Connect [5], which is mainly used in the private sector but provides good virtual classroom that can be customized for teaching purposes. Other tools are: ConferenceXP $\mathrm{P}^{\mathrm{TM}}, \mathrm{Skype}^{\mathrm{TM}}$, $\mathrm{iVisit}^{\mathrm{TM}}$, WebEx ${ }^{\mathrm{TM}}$, GoToMeeting ${ }^{\mathrm{TM}}$, or TokBox ${ }^{\mathrm{TM}}$ to maintain video and audio conferencing between participants, while sharing resources. It is needful to note that this is not an exhaustive list since SVL is growing and evolving quickly.

Nevertheless, the use of SVL is mainly focused, at many Universities, on distance learning and webinars but there is less experience in the use of these tools for face-to-face conventional courses where the lessons are given in a traditional way, but materials and activities are delivered and managed through asynchronous systems. It may seem that in this situation the use of an asynchronous tool is adequate for covering all the learning needs of the students since the faceto-face problem is solved as the student has direct access to the teacher. However, even in this case, synchronous e-learning tools offer good opportunities to enhance learning [6-9]. First of all, SVLs are very useful for virtual tutorships, allowing the student to have a meeting with the teacher without the need to be physically present in the teacher's office. Secondly, they can be used as an interface for collaborative work between students without the need for face-to-face meetings, which become increasingly difficult due to tight schedules. In addition, they can also be used for contacting professionals or academics who can give a seminar to students. Finally, it allows class broadcast to be followed by distance learning students if it is the case (in addition to those present).

In 2010, the Universitat Politècnica de València (UPV) launched Poli[ReunióN] [10], a synchronous communication system based on Adobe Connect ${ }^{\mathrm{TM}}$, to create environments where teachers and students can collaborate in real time through a virtual environment accessible via the Internet. Poli[ReunióN] enriches the existing e-learning UPV system, that is, PoliformaT launched in 2005 as LMS based on Sakai ${ }^{\mathrm{TM}}[11,12]$.

All the authors of this paper belong to the Active Methodologies and Information Technologies (MATI) team, a group of lecturers from the UPV devoted to innovation in higher education. MATI members cover a range of educational disciplines among the UPV degrees: Computer Science, Agronomics, Tourism, and Telecommunications. This paper presents a series of learning experiences using Poli[ReunióN] in our lectures, which involve different courses in various university degrees and along several years for different purposes: (1) support tutoring, (2) promote collaborative activities in the classroom, and (3) teach full lectures. The results of such learning experiences are given and the pros and cons of this platform are discussed from both the lecturer's and the student's points of view. The interest of this paper lays in the fact that it shows work carried out throughout 6 academic years, which permits a clear view of the evolution in the incorporation of SVL tools to the University procedures.

\section{MATERIALS AND METHODS}

\section{Software Used}

Synchronous virtual e-learning tools are those intended for online studies that permit the real-time interaction between students and teachers using some kind of communication channel, like chat, voice, or videoconferencing. SVL tools create a virtual classroom in which students may ask and teachers can reply instantly, making learning a so-called synchronous experience. As compared with asynchronous e-learning tools, the students experience that they are not taking lessons alone, rather they can interact with other classmates and their teachers during the class.

Poli[ReunióN] allows the creation of collaborative environments (virtual rooms) where participants can maintain audio/video conferencing, document/application/desktop sharing as well as receive feedback from other participants (Fig. 1).

The only requirement for attendees is a browser with support for Adobe Flash, which implies that it can be enabled in almost all devices, both in Windows, Linux, and also MacOS. In addition, it is possible to receive content from iOS-based devices (iPhone and iPad) and Android platforms using the specific application of Adobe Connect. To perform these learning experiences, personal computers, or laptops equipped with microphones and headsets are essential for both lecturer and student and webcams for both parties if videoconferencing is needed.

The general workflow when using Poli[ReunióN] is summarized in the following steps. First, the teacher creates a virtual room and provides the link for students to enter the space. The members of a Poli[ReunióN] room have any of the following three roles: host, presenter, and participant. Basically, the creator of the room takes on the role of host and may modify the room configuration (appearance, video quality, etc.) and change the role of others in the room. When students enter the session they are given the role of participants, allowing them to receive content. If the teacher wants a student to display content to the others, it is necessary to change the role of that student to presenter. There may be multiple presenters in a session. In the case of the iPhone and iPad, these devices can only act as receivers of content (receiving the projection of documents, audio, and videoconferencing) but they cannot speak or share their materials. The only way they can actively participate in the session is by using the chat application. 


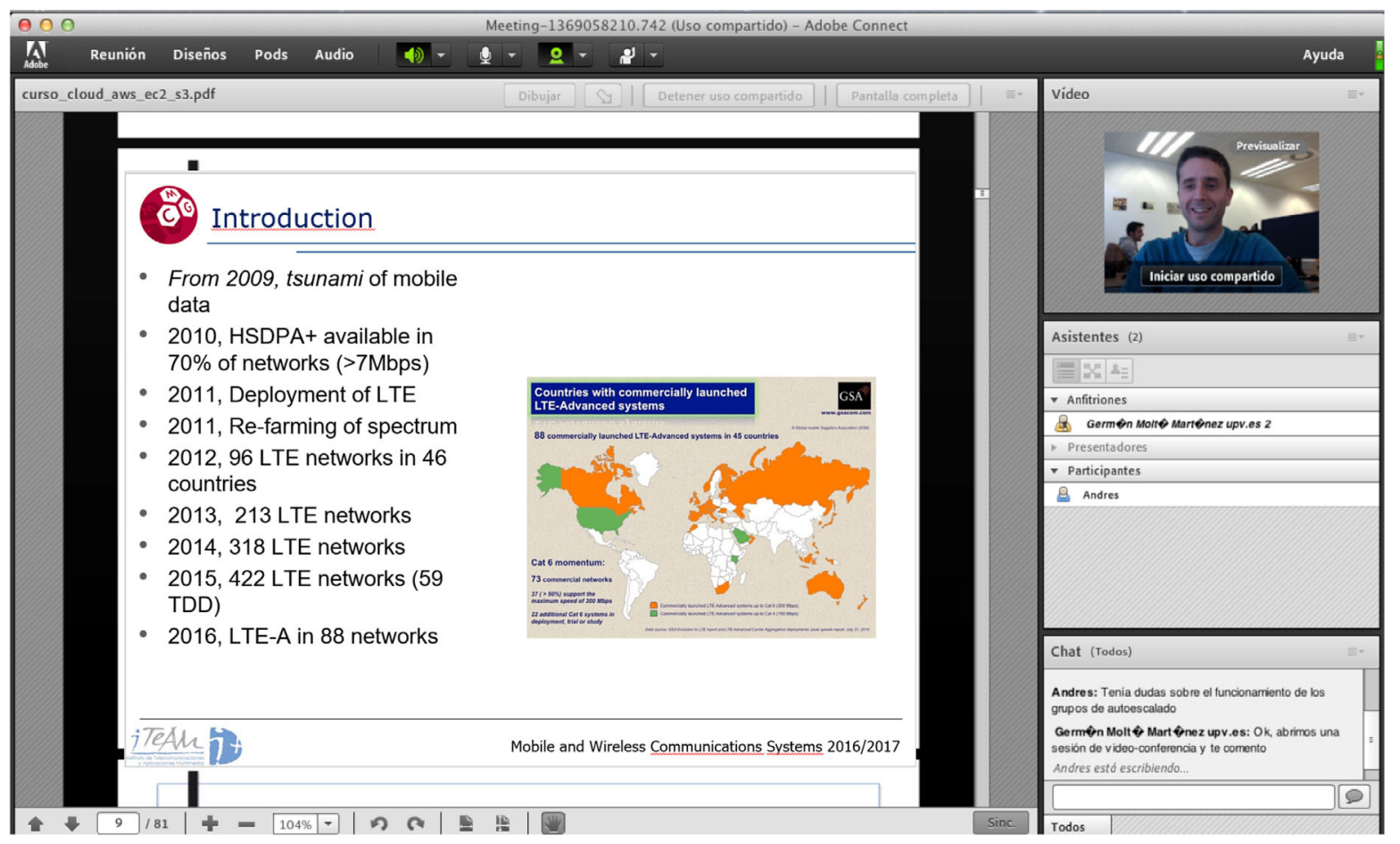

Figure 1 Example of a virtual room projecting a slide. [Color figure can be viewed at wileyonlinelibrary.com]

Virtual rooms have a series of components displayed as windows of different functions called pods. The major functions of Poli[ReunióN] are summarized below:

(1) Audio/video conferencing allows audio and video sessions in real time between multiple participants simultaneously.

(2) Sharing documents allows the teacher, or, more generally speaking, a presenter or a host to open a document (PDF, Word, PowerPoint, etc.) that is then projected on the students' screens. It is possible to force the document to open in full screen mode on the computer screens of the students and allow free navigation through the document. Another option is to let the students view the document in step with the teacher.

(3) A blackboard pod allows the creation of a blank template that students can see in real time, upon which the teacher can draw and make diagrams. It is also possible to superimpose the board while it is sharing a document to make annotations.

(4) File sharing. Through this pod, the teacher can make available documents for students to download onto their computers.

(5) Surveys. The teacher can raise questions to test students' knowledge or gauge their opinion. The teacher can obtain the results in real time and these can be displayed to the students. Thus, the students know the aggregate results of the team members, which eases consensus building. In addition, the teacher may know which student has provided each answer.

(6) Application and Desktop Sharing. The teacher can share an application running on a computer (or the entire desktop) and the rest of the participants can see the application on their screens. In addition, participants can request control of the application shared to allow the student to use the application remotely.

(7) Working Groups. The tool allows manual and automatic creation of working groups among the participants. In this type of work, audio and videoconferences are held between members of each group. This allows collaborative experiences to raise teamwork. The teacher can explain and monitor the activity of each of the groups that will be working in parallel without any interference from the rest.

(8) Chat. The pod enables text-based conversations between participants and also between participants and the teacher.

(9) Chat related to questions and answers. It is possible to link a chat component survey (questions and answers). Thus, the participants raise questions and the host can distribute them to different presenters, who will be responsible for answering them. The response can be made individually, that is, answering only to the student who raised the question, or collectively so that all participants are aware of the answer.

(10) Web Links. This pod allows the teacher to include links to web pages (URLs) that can be opened in the web browser of the student's computer.

After the session, the host closes the virtual room, causing the disconnection of the participants. Poli[ReunióN] sessions can be recorded, allowing you to have a copy on the server of all interactions and pods used, and conversations in audio and video conferences held during the session. 


\section{Subjects Surveyed}

The potential of Poli[ReunióN] has been tested in different courses for students with different backgrounds and degrees of autonomy. In particular, the subjects involved were: English for International Tourism (1st year students), Genetics and Plant Breeding (2nd year), Private Telecommunication Systems (3rd year), Algorithms and Data Structure (2nd year), IP rights in plant breeding (Master course), and a specific course for UPV teachers on the use of collaborative tools for students (Table 1).

Due to the great variety of subjects, number of students, course, and approach, it was impossible to perform the same kind of learning experience in all groups. Each professor designed an experience that $\mathrm{s} / \mathrm{he}$ considered appropriate for the course as outlined in Table 1 and detailed below. However, regardless of the learning experience, after each Poli[ReunióN] session students were asked to complete a questionnaire about the platform (see section Evidence Collection) [13]. The disparity of input is reflected and explained in the data displayed.

\section{Type of Experiences}

Integrating Synchronous Virtual Learning in Tutoring. In general, regardless of the academic discipline, traditional tutoring involves a number of activities that can be summarized as follows:

(1) Having a conversation and eye contact between teacher and student. Closeness and sense of immediacy are key factors in communication and in detecting whether the student understands the given explanations.

(2) Displaying documents and giving presentations that support the explanation of some concept, procedure, or development.

(3) Solving of conceptual or procedural problems. The teacher gives a lecture and/or illustrative examples on paper that the student needs for future reference.

(4) Accessing a reference document (nowadays primarily through the Internet) to consult. In the case of specialized language learning, this implies the use of a web browser to view documents, resolve grammar doubts or vocabulary, and confirm oral production or reception.

All the teachers participating in this experience offered tutorship sessions using Poli[ReunióN] to check its effectiveness for this aim. At the UPV it is possible to offer on-demand tutoring for students. Under this system, students contact the teacher via e-mail and both arrange an appointment. Traditionally the appointment was held at the teacher's office. However, the use of Poli[ReunióN] represents a unique opportunity for teachers and students to coincide in time but not space. As mentioned, each teacher used different features of the tool depending on her/his discipline. A paradigmatic example of virtual tutorships, involving much of the functionality offered by Poli[ReunióN], are those performed in the field of computer science, for example, where the tool was used to solve a query from a student on a theoretical concept of language programming. First, the student requests virtual tutoring expressing his/her time preferences after consulting the teacher's available time slots. The teacher reserves the virtual room in Poli[ReunióN], then notifying the student of the time and the link for the appointment. Eventually, teachers and students enter and configure the virtual room, and, if necessary, the microphone, speakers, and webcam are set up. Then an audio/ video-conference session can be established where the student can ask the teacher questions. The latter can share documents or project some slides (PowerPoint, PDF) on which a series of notes can be displayed with the aim of clarifying a specific explanation. With regard to this, the use of graphics tablets provides a basic advantage when facilitating the use of the tool. The teacher can force a web browser to open so that the student is referred to a specific section on language documentation programming or is directed to a teaching video (learning object), where the issue raised by the student is addressed or they can share a programming application to check for possible problems.

Integrating Synchronous Virtual Learning for Collaborative Work. Poli[ReunióN] was also tested for its use in collaborative work. In this section, the different e-learning experiences performed in each subject are explained. Taking into account the range of subjects covered, different activities were adapted to each subject.

English for International Tourism Experience. The final study on the use of Poli[ReunióN] within the context of conventional classes was the use of this tool for a collaborative experience in the learning of languages. Of interest was the testing of the tool to establish its possibilities for communication in a third language in this type of setting, since students tend to be reluctant to use a foreign language until their level of proficiency is high, and such is rarely the case for first year students. The use of Poli[ReunióN] in an English learning environment was set with three different objectives in mind: (1) it aimed to promote communication among students and between the students and the teacher, (2) it was also intended to test the practicality of allowing students to work on listening skills at their own pace, and (3) it proposed an e-learning collaborative activity, to help improve student maturity and self-

Table 1 Set of Experiments and Aims Covered in This Paper

\begin{tabular}{|c|c|c|c|c|c|}
\hline \multirow[b]{2}{*}{ Degree } & \multirow[b]{2}{*}{ Target students } & \multirow[b]{2}{*}{ Lecture } & \multicolumn{3}{|c|}{ Poli[Reunión] used for ${ }^{\mathrm{a}}:$} \\
\hline & & & Tutorship & Collaborative work & Webinars \\
\hline Tourism management & 1st year & English for international tourism & + & + & - \\
\hline Agricultural engineering & 2nd year & Genetics and plant breeding & + & - & + \\
\hline Informatics engineering & 2nd year & Algorithms and data structure & + & + & - \\
\hline Telecommunication engineering & 3rd year & Private telecomunication systems & + & - & + \\
\hline Master in plant breeding & Master & IP rights in plant breeding & - & - & + \\
\hline Innovation courses & Teachers & Collaborative tools for students & - & - & $t^{\mathrm{b}}$ \\
\hline
\end{tabular}


confidence [14] as well as student involvement, satisfaction and engagement. The exercises proposed were related to these aims. The learning experience was entirely envisaged as a virtual class. The purpose of it was to grant students the appropriate time and means to complete a listening comprehension activity depending on their skills. Then, through collaborative work, they could fill in any missing information they might have. Firstly, a video was shared with the students so that they could actually watch it and listen to it in their own computers. Then, students had to complete their own listening comprehension questions, given to them, again, using the sharing tool offered by Poli[ReunióN]. Thirdly, they were separated into groups in order for them to check and correct their answers. Finally, one only document was shared by each group.

Algorithms and Data Structure Experience. For this subject an activity of collaborative programming work using Poli[ReunióN] was tested. This subject comprises the fundamentals of the Java programming language and the management of algorithms and data structures. Practical skills are required to ensure an optimum learning process. In this respect, students are highly motivated when programming in the classroom. To perform this learning experience, a PC connected to a slide projector (to show the content of the Poli[ReunióN] session) and a laptop connected to a Wi-Fi system, were required. Students joined the session with their own laptops and, in some cases, even iPhones (as explained, when using the latter they were unable to exchange contents, and could only receive information), all students were in the same classroom. The methodology used was as follows: first, the lecturer displayed a programming code with a range of mistakes (both basic and mere typesetting mistakes) through Poli [ReunióN]'s functionality of sharing applications. The developing environment run on the lecturer's computer and the students could view the display of the program both on their screens and through a projector. Students had to identify the mistakes and ask for the control of the application through the tool in order to correct them. Then, the rest of students were able to watch the changes made by their fellow student in two ways: projected directly onto the slides screen and on their own laptops. To encourage students to participate in the trial, it was planned as a contest. Thus, the first student to detect an error was allowed to correct the source code. If that student failed to correct it, another student could ask for permission and take control. In this manner, students collaborated to solve problems. This experiment was performed twice and involved a total of 18 students.

Synchronous Virtual Learning as Substitute of Conventional Classes, Webinars. The last experience was about using Poli [ReunióN] as a platform for synchronous lecturing, or webinars. Private Telecommunication Systems Experience. The synchronous e-learning experience in the subject Private Telecommunication Systems was planned for two sessions. This subject is taught in the final course and aims to describe wireless technologies. The teaching methodology is primarily based on master's lessons using slide presentations. The two Poli[ReunióN] sessions were planned as follows. In the first one, all students remained with the teacher in a classroom equipped with computers and headsets in order to get familiarized with this e-learning tool. This session was assisted by a laboratory technician who helped all the students to set up each piece of equipment. In the second session, some of the students stayed at home following the lesson virtually through Poli [ReunióN], while the lecturer was in the classroom with the rest of students acting as control population. Therefore, the learning experience consisted of teaching a standard class in attendance with part of the students attending on-line.

Genetics and Plant Breeding Experience. For the subject a similar learning experience was set up. After an initial class explaining the use of the Poli[ReunióN] tool, a group of 10 students was divided into two groups, with one group following the lesson in the class, called C-students (conventional group). Whereas, the other group, $\mathrm{V}$-students (virtual group), equipped with laptops, followed the same class via Poli[ReunióN] from another location of the University. This learning experience was repeated with four groups of students. As such, the learning experience was tested four times. Each lesson was chaired by a lecturer, equipped with a laptop connected to a slide projector and to the Poli[ReunióN] platform. In this way, the lecturer could deliver the lesson simultaneously to both $\mathrm{C}$ - and V-students. V-students were assisted by a second lecturer to help solve any problems with the use of the platform. Once the lesson finished, all students were asked to complete a test about the topics explained in the lesson evaluated on a $0-10$ scale to compare the learning process between both the $\mathrm{C}$ - and $\mathrm{V}$-students. In addition, $\mathrm{V}$-students were asked to complete the poll regarding the user experience with Poli[ReunióN].

IP Rights in Plant Breeding Experience. In this case, students were asked to present an essay on the subject of how to protect their activity as plant breeders taking into account the IP rights. Mainly, the presentations were done in class and discussed by the students. However, as in the Master class there are some distance students, they were presented the opportunity to deliver their presentations via Poli[ReunióN].

Collaborative Tools for Students Experience. Regarding acceptance in the implementation of SVL tools, a study over 6 years of the same course was conducted. In this case, this is a course of $10 \mathrm{~h}$ on the use of collaborative online tools, in which students are university professors. In 2010 and 2011 the course was given fully in face manner, while from 2012 and the three subsequent courses it was taught entirely online, using Poli[ReunióN]. In the last course, in 2016, a novelty was introduced, making one of the five sessions mandatorily in the classroom, while the other sessions were online. An average number of 30 professors attended the course every year.

\section{Evidence Collection}

To automate the process of collecting evidences of the use of the Poli[ReunióN] tool, it was decided to implement a system accessible through the Internet in which students could apply for a tutorship, and teachers could register Poli[ReunióN] virtual rooms, manage the tutorships with a calendar and collect evidence related to the student's experience. This system was entirely constructed using the Google Apps tools (Spreadsheets, Mail, Spreadsheets Forms, Sites and Docs) and is available for internal use on the Internet [13]. An important aspect of this tool was that we designed a survey to automatically obtain the views of students immediately following the session. These questions covered issues such as the audio/video quality during the session, types of features used, and whether or not the virtual experience was similar to direct interaction with the teacher.

Only in the case of Genetics and plant breeding there were enough students to perform an experimental design with several repetitions. To those results an ANOVA was applied to check if there existed significant differences among receiving the online 
course or face-to-face. For the course on collaborative tools for students, the UPV automatically distributed an online survey that consists on several question about the resources, methodology, and the software employed for the online class (when applicable).

\section{RESULTS AND DISCUSSION}

As already explained, during several academic years, starting from 2010, different experiments using Poli[ReunióN] including tutoring, virtual classes, and collaborative activities were performed in order to test this synchronous tool for learning. The results have been organized in order to collect the information regarding the use of the SVL tool rather the particular results of each experience. In this sense, the results displayed are the joined data of all the experiences which were evaluated with the same survey. For clarity reasons, the results are organized explaining first the SVL functionalities and technical issues, in second place the specific results for the tutorship, collaborative work, and webinar experiences, in third place the students' general perception of the tool and, finally, the instructors' perception.

\section{SVL Functionalities and Technical Issues}

Here we describe the functionalities used and the main technical issues that arose during the learning experiences. Before using the tool, the camera and microphone site were essential and had to be properly configured. The use of webcams and built-in microphones on laptops was useful for a given time, but was not recommended for regular use due to the low quality of sound and possible echoes introduced. On the other hand, the use of headphones was very important for both students and teacher in order to avoid interferences. This would appear to be obvious, but it can be a difficult problem to solve when a conventional class is taking place and also being followed by on-line students at the same time. When the teacher used headphones, the students present in the classroom were unable to hear the questions/ comments raised by on-line students. In addition, the on-line students usually could not hear the questions and comments of their fellow students in the classroom; neither have visual contact (Fig. 2). In this case, the teacher became a kind of student's

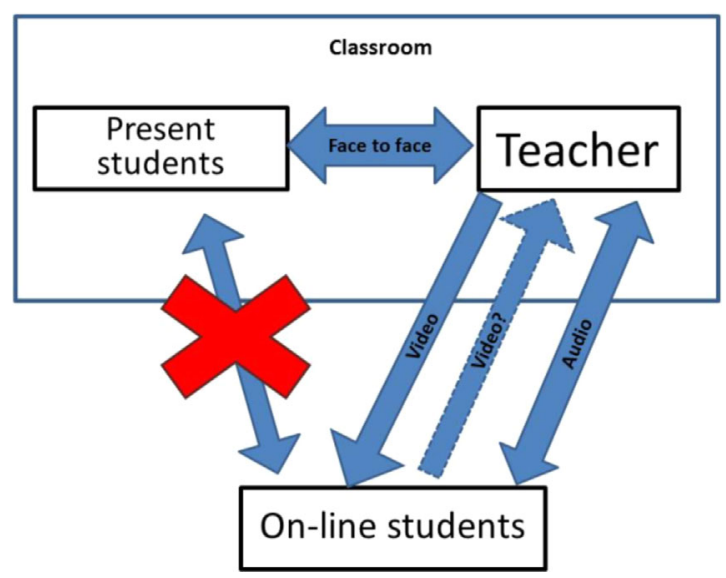

Figure 2 Diagram showing interactions in a conventional class broadcasted by Poli[ReunióN]. [Color figure can be viewed at wileyonlinelibrary.com] emissary, making the rhythm of the lesson less fluent. One solution could be the use of a classroom equipped with cameras and microphones. The second solution, and perhaps a more realistic one, could involve attempting not to mix in situ and on-line lectures. When taking into account the fact that the audio/video is the only interface among users in SVL, it is of paramount importance to pay special attention to them. These initial settings can make the difference between a satisfactory and an unsatisfactory experience [15-17]. In addition to these general considerations, depending on the discipline, other peripheral devices such as tablets proved very useful. This was the case for subjects related to biology or computing, where the teacher frequently has to draw pictures or representations to improve the assimilation of concepts.

As stated in materials and methods, Poli[ReunióN] has a great deal of functionality. From all of these, the most employed during the different learning studies were the audio and video conferencing (audio and video usage in the experiments was $100 \%$ and $70 \%$, respectively, Fig. 3).

These are the basic functionalities that differ from other virtual platforms in which it is possible to chat, but not have a verbal fluent communication, or a face-to-face communication. Among other features, document sharing was the one most employed (60\% of the time), whereas application sharing and the working groups were, generally speaking, less used. Other features such as the chat application or the polls were used only $5 \%$ of the time. Nevertheless, the functionality used is subordinate to the type of subject. Experience has shown that the specific casuistic of each subject requires different functionalities. Thus, for subjects related to programming the software/application sharing is very important. For masters' classes with slide-set support, only the audio and document sharing functions would be needed, whereas for mathematics-related subjects the blackboard pod would be required. On the other hand, the subjects practicing collaborative work would make greater use of the working group and chatting applications. In any case, Poli[ReunióN] has shown sufficient flexibility to accommodate all the needs of the teacher in this multidisciplinary learning-teaching experience. Indeed, it is very important that each teacher spends some time customizing the interface of the virtual session in order for students to be shown only the required functionality. Otherwise, it is hard not to cause confusion with so many pods.

The success of Poli[ReunióN] and, in general, of any synchronous virtual tool, relies heavily on the quality of the connections. In our studies, $84 \%$ of the students felt that the sound quality was either fair $-30 \%$ - or very good $-54 \%-$ (Fig. 4). This percentage falls to $74 \%$ for the same question albeit related to the

Functions used

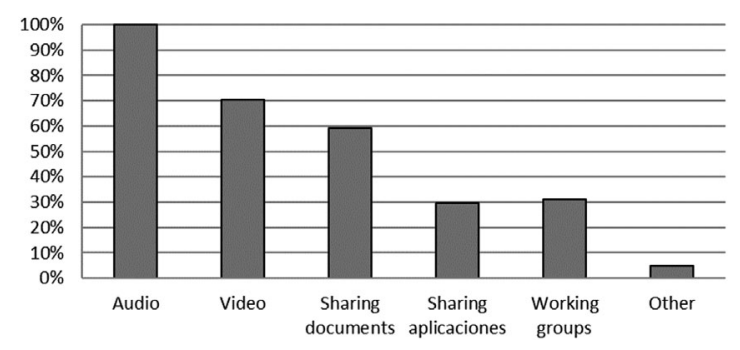

Figure 3 Poli[ReunióN] functions used during the sessions. 


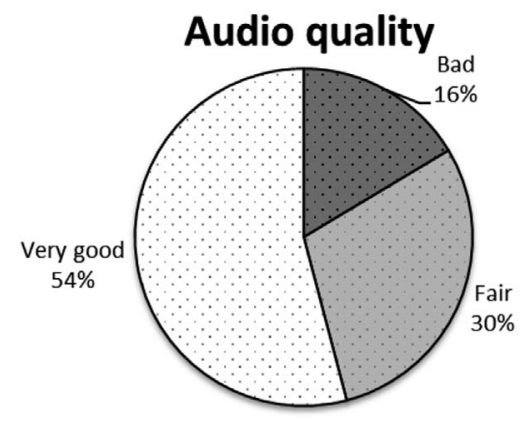

Number of disconnections

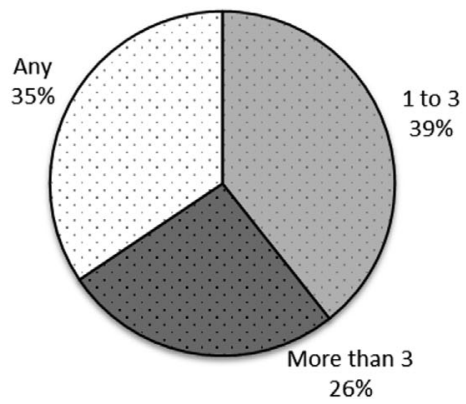

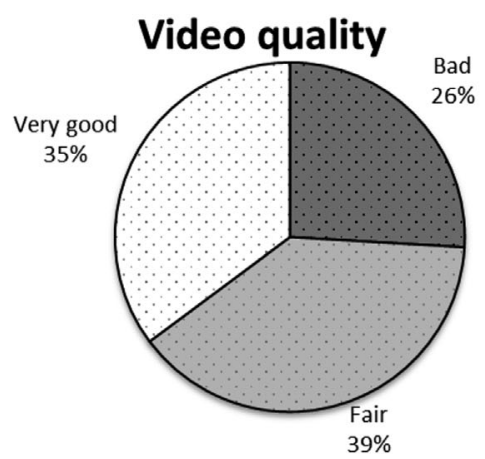

Type of connections

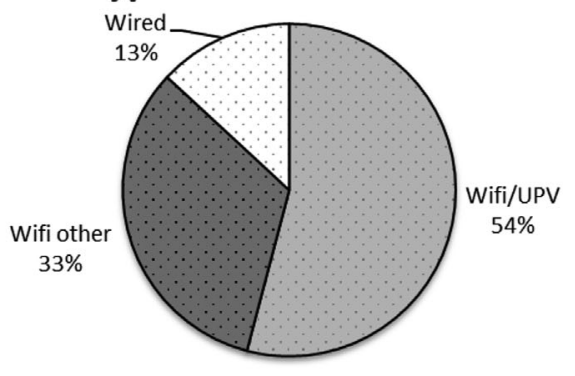

Figure 4 Assessment of the quality of the connections.

image quality of the videoconference. In fact, this being an operation which requires a greater bandwidth, the quality of the connection significantly affects the video user experience. In this sense, it is important to note that $87 \%$ of students who used the system were connected via $\mathrm{Wi}-\mathrm{Fi}$, which may be a limitation depending on the quality of the connection. In addition, $65 \%$ of the students reported having been disconnected during the service. Among those, 26\% were disconnected more than three times which can become very frustrating. Fortunately, reconnection to the room following a disconnection means that the session can be resumed. This can present a great problem for the use of the tool; however, our research and technical conversations with the UPV IT staff suggest that there were specific problems with the 7.5 version of Adobe Connect deployed in the university systems, which caused many connection dropouts. This situation was properly rectified from version $8.0 \mathrm{on}$.

\section{Specific Results From the Tutorship Experiences}

The use of any SVL tool for tutorships is very straightforward, just as their application for company meetings. Subsequently, it was quite easy for Poli[ReunióN] to be adopted by students and teachers. The fact that not very specific devices (simply a microphone and some headsets for students, and possibly a tablet for the teacher) are required and that the connection to the virtual room is quite simple (no software installation is required) helped in the implementation of the tool for tutorship activities. However, in order to avoid technical problems during the sessions, a small demonstration of the use of the tool was necessary prior to firsttime usage by the students.

In general, tutorships were very fluent and disconnections were less frequent than in other learning studies, probably due to the lower number of connected users. On-line tutorships meant a great saving of travelling time. This advantage was specially appreciated by those students who live far from the University and during exam time when students feel that every minute counts. Some of the teachers participating in this experiment teach in different schools. Therefore, they have students located in different towns and they need to conduct tutorships in different locations. By using Poli[ReunióN] those teachers were able to meet all their students at the same point, saving time and energy.

\section{Specific Results From the Webinar Experiences}

Through Poli[ReunióN], it is possible to teach using slides just as in a conventional class. Slides are uploaded in presentation form or PDF format and the application offers tools to point to the slide and highlight items. The management of questions from students is intuitive as they can raise their hands easily through the participants list (a kind of chat list), and it is also easy for the teacher to answer or ask questions.

Taking three different subjects, studies on broadcasting conventional classes through Poli[ReunióN] were performed (in both cases there were students present in the physical classroom and on-line students). As in the case of tutorships, the learning experiences were satisfactory. However, they were slightly more complicated to implement. As previously stated, the fact that on campus and on-line students share the lecture compels the teacher to inform each group of students about the other group's activities and questions (Fig. 2). In addition, the teacher must focus on the classroom, while, at the same time, checking the possible on-line activity (raised hands, possible disconnections. . .). That implies a high level of attention and concentration on the side of the teacher. To succeed in this activity, it is very important to be expert in the use of the platform and have a good plan of the teaching activity. It is also important that the on-line students have experience in using 
the tool. Otherwise, a lecture on Genetics can be transformed into a class on configuring Adobe Connect ${ }^{\mathrm{TM}}$.

In contrast to the tutorship activity, a lecture usually lasts longer and is less personal. Consequently, it is possible for concentration to be lost. In fact, students logging in from home may encounter distractions not present in face-to-face meetings [16]. Cappiccie and Desrosiers [15] suggest that $2 \mathrm{~h}$ sessions allow for plenty of content delivery before students become inattentive. Lectures in our experiences lasted less than $2 \mathrm{~h}$.

Students participating in these learning experiences found that the classes were exciting as they broke the routine and allowed them to use the technological tools that they tend to prefer. Students also liked the idea of studying at home without going to University. However, even if students do prefer to stay at home to attend a class it was not clear if this new situation would affect the learning process. For that reason, in the lectures of "Genetics and Plant breeding" a prior test was conducted for conventional and on-line students to check for possible differences. The study (with the same lesson) was repeated in four different groups. The variance analysis revealed no significant differences between the marks of students of different groups and for the students attending the class and those of the on-line students. The marks for the groups of students receiving the conventional class ranged from 8.20 to 7.35 , whereas the marks for the on-line groups ranged from 8.18 to 7.00 (Table 2). Therefore, we can conclude that the learning process was similar for both methods.

In the Private Telecommunication systems subject, it was impossible to evaluate the effect of the on-line classes on the learning process in comparison with the conventional classes because all the students were at some point on-line students and the marks were obtained from a final exam and not from each lecture. However, the students' marks in the academic years where the learning experience was performed did not significantly differ from those of previous years.

Concerning the evolution of perception along years, the "Collaborative tools for Students" subject was studied. Figure 5 depicts the evolution along the years of the main performance indicators covered by the survey to professors following the course. Results show how their perception of the course, and likely the learning outcomes, worsened significantly when moving from conventional classroom to online mode mode using
Table 2 Results of the Test (0-10 Scale, Mean \pm SE) Made by Students of Genetics and Plant Breeding

\begin{tabular}{lccccc}
\hline & \multicolumn{2}{c}{ Conventional lesson } & & \multicolumn{2}{c}{ On-line lesson } \\
\cline { 2 - 3 } \cline { 5 - 6 } Session & $\begin{array}{c}\text { Number of } \\
\text { students }\end{array}$ & Scores & & $\begin{array}{c}\text { Number of } \\
\text { students }\end{array}$ & Scores \\
\hline S1 & 5 & $7.40^{\mathrm{a}} \pm 0.51$ & 5 & $7.18^{\mathrm{a}} \pm 0.36$ \\
S2 & 4 & $7.35^{\mathrm{a}} \pm 0.86$ & 5 & $7.00^{\mathrm{a}} \pm 0.91$ \\
S3 & 4 & $8.20^{\mathrm{a}} \pm 0.61$ & & $8.18^{\mathrm{a}} \pm 0.26$ \\
S4 & 4 & $7.50^{\mathrm{a}} \pm 0.55$ & 4 & $7.19^{\mathrm{a}} \pm 0.40$ \\
Total/mean & 17 & $7.60^{\mathrm{A}} \pm 0.30$ & & 18 & $7.35^{\mathrm{A}} \pm 0.29$ \\
\hline
\end{tabular}

Values in the same column followed by the same lower-case letters are not significantly different according to ANOVA test $(P<0.05)$.

Values in the same row followed by the same upper-case letters are not significantly different according to ANOVA test $(P<0.05)$.

Poli[ReunióN]. The average perception only recovered in 2016, when moving to a mixed scenario, which allowed maintaining the personal relationship of classical teaching. By analyzing each of the survey items separately, Figure 6 shows how students consider depreciation over years of the educational resources used in the course, which are basically the SVL tool. It seems that the tool is becoming obsolete as the years go by since resources used were considered always worse. However, it seems that, after the first fall of motivation and overall satisfaction, as the years passed perception on the course was improving. The explanation may be in the habit and acceptance of the new reality of online teaching. Nevertheless, the main output of this experience is the fact that the best experience was obtained with the hybrid class mode, with face-to-face and online learning, which exhibits the best results for all parameters.

\section{Specific Results From Collaborative Work Studies}

In addition, we tested the utility of Poli[ReunióN] for collaborative work using the sharing application function in the lectures on Algorithms and Data Structure. The main advantages of Poli [ReunióN] found during this learning experience were: (1) to encourage students to take part in classroom activities as they use the same programming environment, (2) to develop their practical

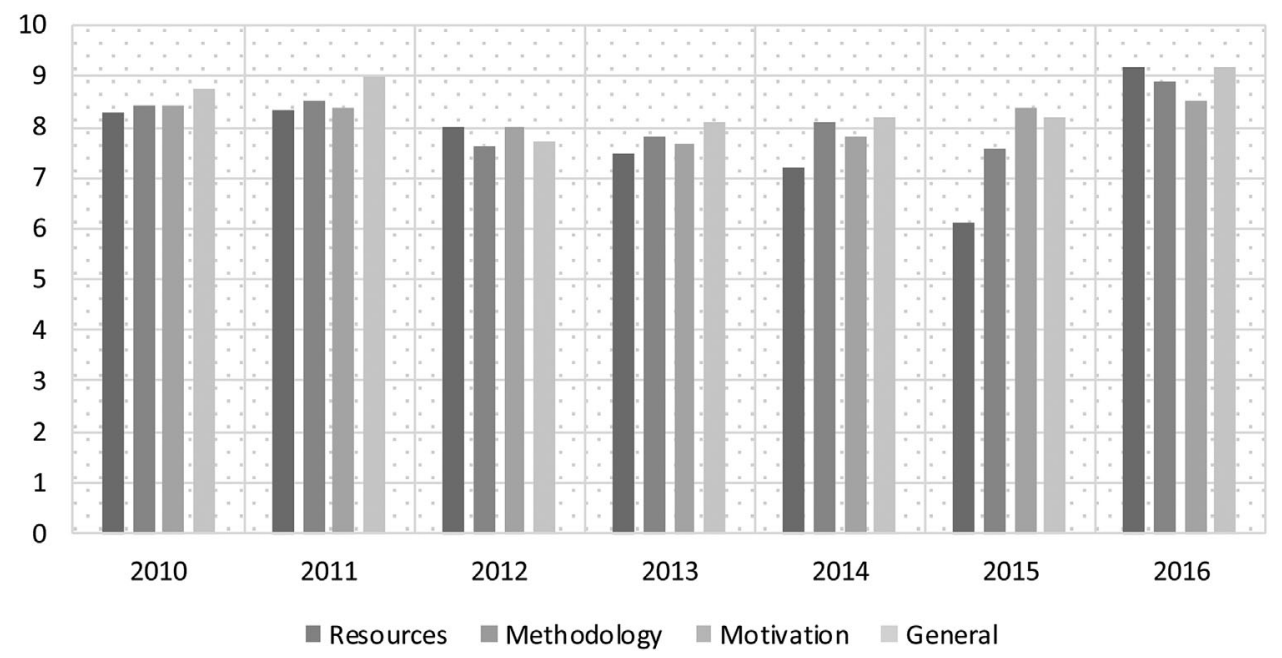

Figure 5 Evolution along years of students experience. 


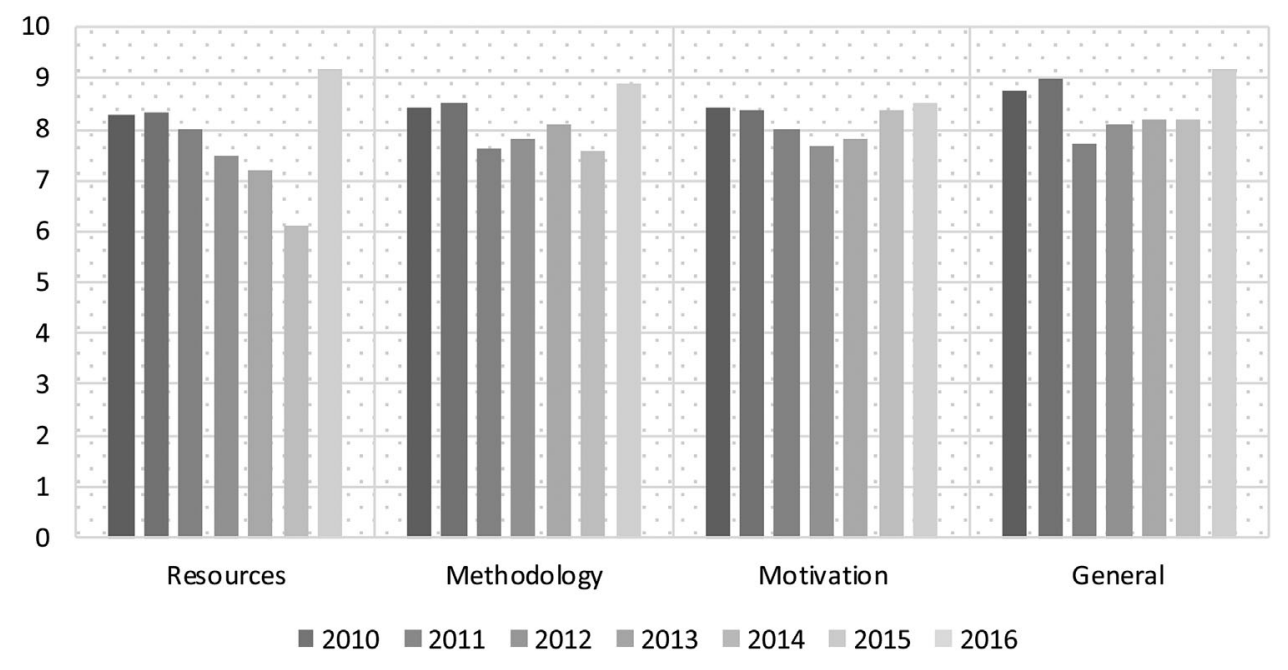

Figure 6 Evolution along years of the different aspects evaluated.

skills as they have to revise and correct a real programming code without assistance, and (3) to simultaneously encourage their competitive spirit and teamwork.

The usefulness of the working groups for learning languages was also tested. An accurate selection of the activities proposed to the students was crucial in obtaining the expected results [18], as well as the appropriate number of classroom participants. The degree of success varied in this exercise. The chat rooms established for discussion proved to be very well accepted and beneficial to students. However, there were some difficulties in using the platform for the listening activities, since not all audio and video formats are accepted. Additionally, students expressed satisfaction about the possibility of working collaboratively in a networked environment. The platform seems to be reliable and well accepted for written and one-to-one oral activities as well as for the sharing documents. Despite the fact that the learning experience was based on a 15 student population, we consider 10 students to be the appropriate size for this type of e-learning session.

Using Poli[ReunióN] for collaborative work avoids some of the problems experienced in conventional classes: keeping the attention of the students was less problematic as all the students were working with the same interface (the computer). Therefore, no different communication means were required. Nevertheless, a key point for the success of this kind of use for SVL is the accurate planning of the activity. We agree with Levy [19] that the six factors to take into account when planning any on-line activity are: the existence of a vision and a plan for the on-line activity, the activity content, the staff training, the helping resources for the students, the student's training and, finally compliance with intellectual property. A deficiency in any of these factors can imply the failure of the entire activity.

\section{Results From the Student's Perspective}

Following each session, regardless of the subject or type of activity, students were asked to complete a questionnaire, the answers of which are now discussed. In general, students showed great enthusiasm for the possibility of this type of communication with either the teacher or other students. When combining all the learning experiences, $78 \%$ of the students found the tool very useful, $18 \%$ useful, and only $4 \%$ disliked it (Fig. 7).

It was hypothesized that a synchronous tool could be very similar to a direct interaction with a teacher in a tutorship or to direct attendance in the classroom. When asked about that, $73 \%$ of the students answered that the use of Poli[ReunióN] can substitute the direct interaction with the teacher following the improvement of the tool, mainly involving connectivity (Fig. 7). This was particularly true for virtual tutoring, which allowed the same work-flow as conventional tutorials and was greatly appreciated
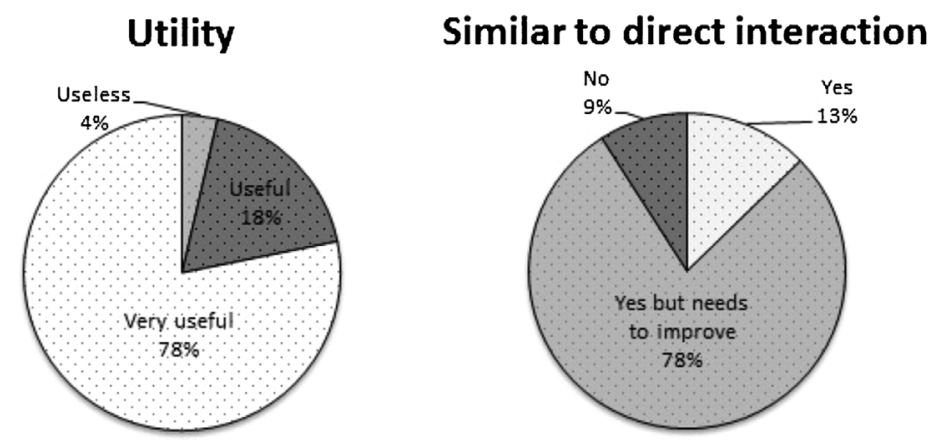

Figure 7 Survey to the students after each usage. 
by the students. In addition, $84 \%$ of the students considered e-learning as a possible candidate for substituting face-to-face classes and a real alternative to tutoring.

These results concur with other experiences with Adobe Connect $^{\mathrm{TM}}$ [20] in which students listed the advantages of this system: (1) face to face contact, (2) not travelling to class, (3) being in the comfort of home, and (4) consultation with the lecturer and peers. In the same study, the following disadvantages appeared: (1) some technical difficulties, (2) connectivity issues, and (3) feeling less attentive. Saitta et al. [17] employed this platform to create an interactive teaching method for undergraduate students at the University of Central Florida. Although only 19 students were employed to gather evidence of satisfaction, $85 \%$ of students reported an increased ability to understand and apply the course material.

\section{Teacher's Point of View and Advice for Users}

From the teacher's point of view, the use of Poli[ReunióN] was quite satisfactory. The main advantages envisaged were: (1) the versatility of use, (2) delocalization of meetings, and (3) an uncomplicated information exchange flow. Whereas, the four main disadvantages observed were: (1) the need for training in the use of the tool, (2) the frequent disconnections, (3) the need for good audio/video equipment, and (4) the lack of visual contact and control if conventional and on-line lectures are shared.

Regarding the advantages, probably the versatility of use is the one most valued by teachers. This versatility makes the SVL tools useful for many kinds of subjects within University degrees. Poli[ReunióN] has proven to be useful for a wide range of applications such as: individual and group tutorships, the teaching of main lectures and collaborative work either in the classroom or at home. This opens the possibility of promoting very different activities adapted to diverse subjects. Apart from these teaching applications, any SVL tool can be used for different purposes within the University context. For example, McConell et al. [16] used Adobe Connect ${ }^{\mathrm{TM}}$ to train professional skills in Professional Learning Communities at High School level. A similar scheme can be used by University lecturers to share experiences and knowledge.

Another advantage involves the delocalization of meetings. The fact that physical distance is no longer a problem makes access to teacher easier for students and can also help teachers to better organize their schedules. Although it was not used during these learning experiences, some teachers suggested the possibility of connecting with other colleagues through Poli[ReunióN] in order to give seminars to students.

As we pointed out previously, to have a satisfactory experience using SVL tools, the settings of the camera and microphone must be optimized prior to the use of Poli[ReunióN]. This refers to one negative aspect that appeared when some students had troubles configuring their microphones, thus being only able to hear the lessons. Fortunately, configuration problems can be solved with good training sessions. However, the most annoying and limiting problem highlighted by the teachers centered on the connectivity problems (which occurred mainly at home due to the weakness of wireless signals). Connectivity problems were difficult to solve and sometimes made communication impossible. These types of problems appeared mainly when many users where connected to audio/video. It seems that the connection problems are now being rectified in the new versions of the software.
Another disadvantage that teachers found when using Poli [ReunióN] for common classes was the lack of visual contact with students, which did not allow the teacher to identify the degree of understanding and motivation. It is hard for a teacher to explain to a screen. This problem can be solved if all the students use videoconferencing; however, this is not feasible with a large number of students. Therefore, new ways of assessing the effectiveness of the communication must be employed (such as stating an affirmative when talking on the phone). In this sense, on-line collaborative activities were more satisfactory for the teacher because during these types of activities the teacher acts as facilitator and is not merely another source of information.

In addition, Poli[ReunióN] is not directly integrated with PoliformaT. This means that, for example, there is no automated way to know which students attended each session from PoliformaT. However, this information can be obtained directly from the Poli [ReunióN] meeting, which can also be recorded for further postprocessing. Inviting the in-class students to a Poli[ReunióN] meeting can be done either via e-mail with the link to the meeting and/or by showing a QR code with the meeting link information in case only the students attending this session have to be invited.

Finally, it is important to point out that student-to-student interaction is an important part of learning. Indeed, peer instruction is now considered fundamental for learning and a complementary technique to traditional approaches based on teacher-student interaction. Peer instruction can also be achieved with a SVL (Synchronous Virtual e-Learning Tool) such as Adobe Connect since work groups can be configured so that students interact among themselves to accomplish a certain task specified by the lecturer and leveraging the existing pods such as chat, blackboard, file sharing, and audio/video conferencing among students distributed in several work groups within the same Adobe Connect meeting.

Indeed, Virtual Learning Environments (VLEs) are increasing in importance not only for distance learning, but also for conventional learning environments. In fact, some authors, such as Hiltz and Turoff [21], argue that Internet-based learning is a new social process that is becoming a substitute both for distance learning and traditional face-to-face lessons. Nevertheless, from our point of view VLEs do not substitute the role of the teacher. In fact, as Warschauer et al. [22] claimed with regard to networking and the internet "it is the teaching that makes the difference." However, the role of new technologies in the teaching context is without question. For example, Smith and Cline [23] describe a classroom-based course in the Concepts of Biology conducted solely using electronic technologies where students were required to bring laptops to their classes. It is hard not to think that this is going to be the future for higher education.

\section{CONCLUSIONS}

In this paper, the results of a set of learning experiences using an Adobe Connect ${ }^{\mathrm{TM}}$ based virtual learning environment in the Universitat Politècnica de València have been presented. In particular, Poli[ReunióN] has proven a useful tool for distance and conventional learning, mainly because of: (1) its synchronous nature, facilitating the performance of tutorships without the need for the student to visit the teacher's office, (2) the possibility of cooperative work among students, and (3) its versatility, allowing different types of activities (writing, taking control of someone else's computer, listening, chatting, etc.). Poli[ReunióN] was highly appreciated by the students, however, the teachers 
discovered some disadvantages and were, in general, more critical with the tool. Despite the fact that Poli[ReunióN] is a tool available at the Universitat Politècnica de Valencia, the experiences are useful for other education professionals who would like to implement VLE in their teaching with any of the software packages available in the market.

As regards our learning experiences, we can conclude that SVL is currently a useful tool for tutorships, for collaborative work both in the classroom and at home, and for distance learning. It does not work so well when trying to execute the same class conventionally and on-line, especially due to the difficulty of having two types of audiences simultaneously (on campus and on-line). The SVL is much appreciated by the students and teachers can adapt to it without too many problems. Nevertheless, new teaching tools require new methodologies and adaptations. Therefore, more studies must be carried out in the future in terms of assessing learning effectiveness and to adjust the teaching methods in order to optimize the benefits of using these new tools.

\section{ACKNOWLEDGMENTS}

The authors would like to thank the "Vicerrectorado de Estudios y Convergencia Europea" (VECE) of the UPV for their financial support of the project Experiencias Multi-Disciplinares de Integración de Aula Inversa para el Desarrollo de Competencias Transversales.

\section{REFERENCES}

[1] D. R. Garrison and T. Anderson, E-learning in the 21st century: A framework for research and practice. Routledge Falmer, London, 2003.

[2] A. Beuchot and M. Bullen, Interaction and interpersonality in online discussion forums, Dist Educ 26 (2005), 67-87.

[3] V. P. Dennen, A. A. Darabi, and L. J. Smith, Instructor-learner interaction in online courses: The relative perceived importance of particular instructor actions on performance and satisfaction, Dist Educ 28 (2007), 65-79.

[4] D. R. Garrison and M. Cleveland-Innes, Facilitating cognitive presence in online learning: Interaction is not enough, Am J Distance Educ 19 (2005), 133-148.

[5] AdobeConnect ${ }^{\mathrm{TM}}$ (2012). http://www.adobe.com/es/products/connect/

[6] S. Bondi, T. Daher, A. Holland, A. R. Smith, and S. Dam, Learning through personal connections: Cogenerative dialogues in synchronous virtual spaces, Teach High Educ 21 (2016), 301-312.
[7] Y. M. Huang, Y. H. Kuo, Y. T. Lin, and S. C. Cheng, Toward interactive mobile synchronous learning environments with contextawareness service, Comput Educ 51 (2008), 1205-1226.

[8] Y. Park and C. Bonk, Synchronous learning experiences: Distance and residential learner. Perspectives in a blended graduate course, J Interact Online Learn 6 (2007), 245-264.

[9] M. Xenos, N. Avouris, V. Komis, D. Stavrinoudis, and M. Margaritis, Synchronous collaboration in distance education: A case study on a computer science course. Proc IEEE Int Conf Adv Learn Technol 1 (2004), 500-504.

[10] PoliReunión (2016). Reserva de Salas Virtuales. https://polireunion. upv.es/

[11] PoliformaT, (2016). http://poliformat.upv.es

[12] J. Clemente, C. Escribá, and J. M. Buitrago, Dimensiones clave en la satisfacción con los entornos virtuales de aprendizaje en la enseñanza universitaria: el caso de PoliformaT, Revista mexicana de investigación educativa 15 (2010), 849-871.

[13] MATI-UPV. (2016). https://sites.google.com/site/matiupv/

[14] M. L. Carrió, Definición y características del aprendizaje colaborativo asistido por ordenador. In: Aprendizaje colaborativo asistido por ordenador, M. L. Carrió (Ed.), Blauverd impressors, Valencia, Spain, 2006, pp 9-35.

[15] A. Cappiccie and P. Desrosiers, Lessons learned from using adobe connect in the social work classroom, J Technol Hum Serv 29 (2011), 296-302.

[16] T. J. McConnell, J. M. Parker, J. Eberhardt, M. J. Koehler, and M. A Lundeberg, Virtual professional learning communities: Teachers' perceptions of virtual versus face-to-face professional development, J Sci Educ Technol 22 (2012), 267-277.

[17] E. K. H. Saitta, M. A. Bowdon, and C. L. Geiger, Incorporating service-learning, technology, and research supportive teaching techniques into the university chemistry classroom, J Sci Educ Technol 20 (2011), 790-795.

[18] A. Konstantinidis, T. H. Tsiatsos, and A. Pomportsis, Collaborative virtual learning environments: Design and evaluation, Multimed Tools Appl 44 (2009), 279-304.

[19] S. Levy, Six factors to consider when planning online distance learning programs in higher education. Online J Dist Learn Adm 6 (2003), 1-19.

[20] T. Väljataga, Students' learning environments for distance international collaboration. State-of-the-art and future directions of smart learning, Springer Singapore (2016), 211-220.

[21] S. R. Hiltz and M. Turoff, Education goes digital: The evolution of online learning and the revolution in higher education, Commun ACM 48 (2005), 59-64.

[22] M. Warschauer, H. Shetzer, and C. Meloni, Internet for english teaching. TESOL Publications, Alexandria, VA, USA, 2000.

[23] M. L. Smith and M. A. Cline, Inexpensive options for a high-tech learning environment, J Sci Educ Technol 20 (2011), 785-789.

\section{BIOGRAPHIES}

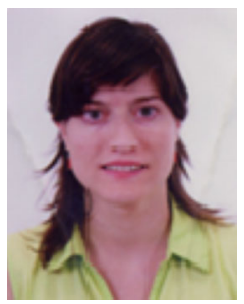

Ana Fita was born in 1979, in Valencia (Spain), where she graduated in Agriculture Engineer and obtained her PhD in Plant Breeding. She is associate professor at the Universitat Politècnica de València (UPV). She has been teaching for 12 years a wide variety of subjects related to Genetics, Plant Breeding and Plant Genetic Resources, such as: 'Genetics and Plant breeding', 'Plant genetic resources', 'In vitro culture and plant transformation', 'Plant variety laws and commercial production of plant material' at graduate and Master degrees of the UPV. At the moment she is the academic director of the Master in Plant Breeding at UPV. She has tutorized 27 graduate and master theses, and has participated in seminars in several European Universities. She is part of MATI, an innovation group devoted to improve University teaching, with this group she has participated in eight educational innovation projects from which several congress publications have been released. She has been also awarded by the American Society for Horticultural Science (ASHS) and the Valencian Government (Excellence Teaching Award at University Level 2010). In addition, Ana Fita leads the Root Breeding group at the Intituto de Conservación y Mejora de la Agrodiversidad Valenciana, COMAV, at UPV. Her research includes breeding vegetables for improved root systems, improving our understanding of root architecture and its relationship with resistance to biotic and abiotic stresses. At the moment she is studying the genotype/soil/root interaction in Capsicum annuum L. and the effects of abiotic stress on fruit quality. 


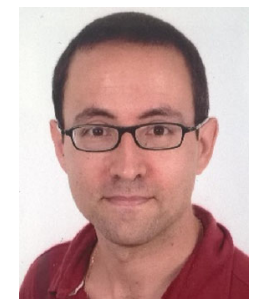

Dr.-Ing. Jose F. Monserrat (H-index 16) received his MSc degree with High Honors and $\mathrm{PhD}$ degree in Telecommunications engineering from the Universitat Politècnica de València (UPV) in 2003 and 2007, respectively. He was the recipient of the First Regional Prize of Engineering Studies in 2003 for his outstanding student record receiving also the Best Thesis Prize from the UPV in 2008. In 2009 he was awarded with the best young researcher prize of Valencia. He is currently an associate professor in the Communications Department of the UPV. His current research focuses on the design of future $5 \mathrm{G}$ wireless systems and their performance assessment. He has been involved in several European Projects, being especially significant his participation in NEWCOM, PROSIMOS, WINNER+, and METIS/ METIS-II where he led the simulation activities. He also participated in 2010 in one external evaluation group within ITU-R on the performance assessment of the candidates for the future family of standards IMTAdvanced. He co-edited two special issues in IEEE Communications Magazine on IMT-Advanced and 5G technologies and is co-editor of the Wiley book "Mobile and wireless communications for IMT-Advanced and beyond" and the Cambridge book "5G Mobile and Wireless Communications Technology". Jose Monserrat is senior member of the IEEE, holds 6 patents and has published more than 50 journal papers. Currently the group headed by Prof. Jose F. Monserrat consists of five Postdoctoral fellows, eight PhD students, and two Master students.

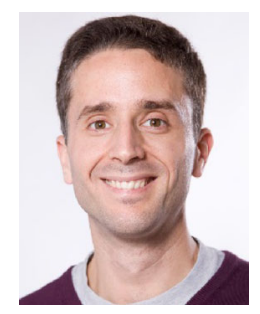

Germán Moltó received the $\mathrm{BSc}$ and $\mathrm{PhD}$ degrees in computer science from the Universitat Politècnica de València (UPV), Spain, in 2002 and 2007. He is a member of the Grid and High Performance Computing research group (GRyCAP) at the Institute for Molecular Imaging (I3M) since 2002. He is also associate professor at the Department of Computer Systems and Computation (DSIC) at UPV. He has participated in several European projects and led National research projects in the area of Cloud Computing. His research interests broadly lie in the areas Cloud Computing, Scientific Computing and Technology-Enhanced Learning. He is member/coordinator of the Active Methodologies and Information Technologies (MATI) education research team where he has been responsible and participated in several projects to research on technologies applied to education.

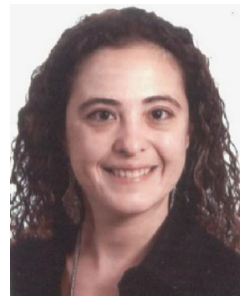

Eva M. Mestre is a professor at Universitat Politècnica de València. She studied English and Spanish Literature. Since her $\mathrm{PhD}$ thesis in Linguistics based on the pragmatic implications of errors in English as a second language, her research has focused on error analysis, English learning in higher education, and corpus management, including computational linguistics, as a member of the GALE research group. She participates in two National research projects related to Pragmatics and higher education and computational linguistics. She was a visitor researcher in several European and American universities. She is currently director of the panel on pragmatics for the Spanish Society for Applied Linguistics and director of the panel on English for Specific Purposes for the Spanish Association for Corpus Linguistics.

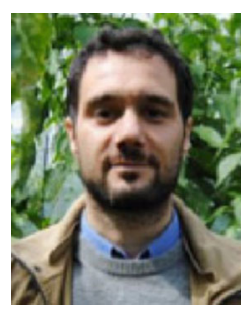

Adrian Rodríguez-Burruezo was born in 1974, in Murcia (Spain), where he graduated in Agriculture Engineer (1997). Later (2003) he obtained his $\mathrm{PhD}$ in Plant Breeding in the Universitat Politècnica de València (UPV). He is associate professor at the UPV. He has been teaching a range of subjects related to Genetics and Plant Breeding and Horticulture, such as: 'Genetics and Plant breeding', 'Plant Breeding', 'Horticultural Crops', 'Forestry Genetics', or 'Population Genetics' at graduate and Master degrees of the UPV. He has tutorized 30 graduate and master theses and two $\mathrm{PhD}$, and has given several seminars in European Universities. Adrian Rodríguez-Burruezo leads the Capsicum Breeding group at the Intituto de Conservación y Mejora de la Agrodiversidad Valenciana, COMAV (UPV). His research includes breeding Capsicums for improved fruit quality (flavor traits: pungency and volatiles; bioactive compounds: antioxidants, carotenoids), tolerance to abiotic stresses (e.g., low temperatures, drought, or salt stress), adaptation to low input conditions (including organic conditions). He has published over 60 scientific papers, 30 of them in ISI journals, in the categories of Horticulture and Agriculture. He has been also awarded by the American Society for Horticultural Science (ASHS) and the Spanish Society for Horticultural Science (SECH), as well as by the Valencian Government (Excellence Teaching Award at University Level 2010). 